Психология. Журнал Высшей школы экономики.

2020. T. 17. № 4. C. 630-644. DOI: 10.17323/1813-8918-2020-4-630-644

\title{
ИНКУБАЦИЯ В РЕШЕНИИ ТВОРЧЕСКИХ ЗАДАЧ: ГИПОТЕЗЫ И ПЕРСПЕКТИВЫ ИССЛЕДОВАНИЙ
}

\author{
Н.М. ЛАПТЕВА ${ }^{\mathrm{a}}$ \\ ${ }^{a}$ ФГБУН «Институт психологии РАН», 129366, Москва, ул. Ярославскал, д. 13, к. 1
}

\begin{abstract}
Резюме
Настоящая работа посвящена одному из важнейших феноменов в психологии творчества - феномену инкубации при решении задач. Инкубацией исследователи называют перерыв в решении задачи, который способствует нахождению ответа, несмотря на отсутствие его сознательного поиска. Статья представляет собой обзор теоретических подходов к объяснению инкубации и экспериментальных работ, освещающих с разных сторон когнитивные механизмы данного явления. В ней анализируются основные гипотезы о когнитивных механизмах периода инкубации, такие как гипотеза селективного забывания, гипотеза бессознательной работы, гипотеза внешних ключей, гипотеза ухода внимания, и их экспериментальные свидетельства. Обзор содержит основные результаты метааналитических работ, в которых были обнаружены доказательства существования рассматриваемого феномена, а также подробно рассмотрены факторы, влияющие на величину эффекта инкубации, такие как тип основной и инкубационной задачи, длительность подготовительного и инкубационного этапа. Особое внимание уделено описанию современных нейрокогнитивных исследований творческого мышления. Эти работы направлены на детальное изучение тех систем мозга, которые задействованы во время инкубационного перерыва, что открывает новые возможности для более глубокого изучения процессов, происходящих во время инкубационного перерыва. Например, в некоторых из этих работ было обнаружено увеличение активности дефолт системы мозга, а также уменьшение активности системы исполнительного внимания. В заключении сделан вывод о текущем состоянии исследований в этой области, а также предложены наиболее перспективные направления для будущих работ, в которых еще предстоит найти ответы на спорные вопросы.
\end{abstract}

Ключевые слова: творчество, инкубация, теория селективного забывания, гипотеза бессознательной работы, дефолтная система мозга, нейрофизиологические механизмы.

В связи со стремительным развитием старых и возникновением новых технологий с каждым годом в обществе возрастает значимость умственного труда. Это ставит современную науку перед необходимостью исследования когнитивных механизмов мышления. Творческое мышление имеет особую специфику, поскольку целенаправленная сознательная работа над творческой задачей часто не приводит к желаемому результату. Появлению креативного решения может способствовать период инкубации, во время которого человек отдыхает или занимается другим делом, не пытаясь специально найти ответ на задачу.

Работа выполнена при частичной финансовой поддержке грантов Российского фонда фундаментальных исследований (РФФИ) КОМФИ № 18-00-00569 и № 18-00-00939. 
На сегодняшний день в психологии накоплено немало материала, который проясняет когнитивные механизмы инкубационного периода при решении творческих задач. Хотя бо́льшая часть работ принадлежит зарубежным автоpam (Smith, Blankenship, 1991; Dijksterhuis, Meurs, 2006; Gilhooly et al., 2012), в последнее время стали появляться важные отечественные работы (Валуева, 2016; Валуева, Ушаков, 2017; Величковский и др., 2019; Коровкин и др., 2016). В настоящем обзоре приведены основные результаты таких исследований.

\section{Инкубация как одна из стадий творческого процесса}

Первые описания феномена инкубации можно встретить в самоотчетах выдающихся ученых, таких, например, как А. Пуанкаре, К. Гаусс, Г. Гельмгольц. В своих работах они описывали творческий процесс, благодаря которому произошли важные научные открытия (Пуанкаре, 1981; Бюлер, 1989; Лапшин, 1999).

А. Пуанкаре не только представил подробное интроспективное описание феномена инкубации, но и предложил объяснительную модель творческого мышления, которая не потеряла своей актуальности в настоящее время (Пуанкаре, 1981). Для ее построения ученый использовал физическую аналогию - модель идеального газа, молекулы которого он сравнивал с понятиями в нашем уме. В начальный момент времени все молекулы-понятия неподвижны. Первоначальная сознательная работа над проблемой отрывает молекулы от стенок и запускает их движение, а спустя некоторое время молекулы движутся уже автономно, и ведущую роль на себя берет бессознательный процесс. Молекулы-понятия хаотически ударяются друг об друга и образуют новые сочетания - идеи. Некоторые из них могут обладать красивой упорядоченной структурой, и их появление в сознании может сопровождаться чувством «озарения» (Ушаков, 2000).

Термин «инкубация» был популяризирован позднее благодаря работе Г. Уоллеса, в которой им были описаны четыре стадии творческого процесса (Wallas, 1926, p. 31-39). На первой стадии («подготовка») человек пробует сознательно решить стоящую перед ним задачу, накапливая необходимую информацию. После первых безуспешных попыток решения следует вторая стадия («инкубация»), во время которой прекращаются сознательные попытки решить задачу. Период инкубации, во время которого происходит скрытая неосознанная работа, приводит человека к третьей стадии («озарение»). В этот момент креативная идея неожиданно появляется в сознании. На последнем четвертом этапе («верификация») происходит сознательная проверка и разработка идеи (Ушаков, 2000).

Современные эмпирические исследования инкубации построены в рамках двух экспериментальных парадигм. Первая парадигма, которая получила название «отсроченная инкубация», предполагает следующую схему построения эксперимента. Участников делят на две группы - экспериментальную и контрольную. Испытуемые экспериментальной группы пробуют сначала решить все задания, затем делают инкубационный перерыв, после которого 
предпринимают вторую попытку решения. Во время инкубационного перерыва испытуемые либо отдыхают, либо занимаются решением других задач. Испытуемые контрольной группы предпринимают повторную попытку решения задач сразу же после первой, работая без перерыва. Для того чтобы определить, повлияла ли инкубация на успешность решения задач, вычисляется эффект инкубации. Он рассчитывается как разница между успешностью решения задач между группами при второй попытке (Валуева, 2016). Эксперименты, построенные в рамках второй парадигмы, названной «немедленная инкубация», отличаются тем, что испытуемые экспериментальной группы делают инкубационный перерыв сразу же после получения инструкции к заданию (Dijksterhuis, Meurs, 2006). В некоторых работах авторы использовали оба типа инкубации (Gilhooly et al., 2012; Nordgren et al., 2011). В метааналитических работах было показано, что эффект инкубации может наблюдаться как в случае отсроченной инкубации, так и в случае немедленной (Sio, Ormerod, 2009; Strick et al., 2011).

\section{Гипотетические механизмы инкубации}

Феномен инкубации до сих пор вызывает немало споров среди исследователей. Почему отвлечение внимания от решения задачи может существенно облегчать поиск ответа? Какие когнитивные механизмы стоят за данным феноменом? Многие ученые, пытаясь ответить на вопросы о механизмах инкубации, предлагали свои теоретические гипотезы, нередко противоречащие друг другу. Некоторые из этих предположений были подвергнуты экспериментальной проверке.

Выдающийся отечественный ученый Я.А. Пономарев в своей модели двухполюсной организации когнитивной системы выдвинул важнейшие теоретические постулаты, пролившие свет на механизмы творчества. Он полагал, что порождение новой идеи осуществляется благодаря последовательной работе интуитивного и логического режимов мышления на различных этапах решения задачи. Нахождение общего принципа решения в момент озарения происходит на бессознательном уровне благодаря интуитивному режиму (Ушаков, 2006). В приведенных выше научных идеях Я.А. Пономарева содержатся положения, ценные для объяснения механизмов инкубации. Эту стадию творческого мышления можно описать в терминах его теории как переход в режим работы интуитивных, бессознательных процессов поиска ответа. Именно в этом режиме мышления человеку становятся доступны те многочисленные знания и связи, которые были сформированы в прошлой деятельности помимо его сознательных целей. Они получили название «побочный продукт действий» (Пономарев, 1967). Представления ученого получили свое развитие в некоторых современных исследованиях, например, в исследовании Е.А. Валуевой (Валуева, 2016). В нем была эмпирически проверена модель, согласно которой роль инкубации заключается в устранении причин, мешающих осознанию уже существующего в имплицитном виде решения (Валуева, Ушаков, 2017).

Существуют и другие направления отечественных исследований. В одной из экспериментальных работ С.Ю. Коровкина с коллегами при выявлении 
особенностей динамики загрузки рабочей памяти на этапе инкубации был обнаружен значимо меньший вклад рабочей памяти в решение инсайтных задач, по сравнению с алгоритмизированными. Это может свидетельствовать о низком уровне произвольного контроля и отсутствии выполнения последовательных операций во время инкубационного перерыва (Коровкин и др., 2016).

Возникновение многочисленных подходов к объяснению феномена инкубации сделало актуальной задачу их классификации. Е. Сигал в своей работе 2004 г. выделил несколько типов гипотез, претендующих на объяснения рассматриваемого феномена. Первый тип, который он выделил в своей классификации, - гипотезы автономных процессов. К ним он отнес те объяснения, которые предполагают наличие каких-либо изменений в протекании когнитивных процессов во время периода инкубации, благоприятно сказывающихся на поиске ответа. Второй тип гипотез - гипотезы внешних ключей. Согласно этим предположениям, эффект инкубации зависит от того, встретится ли решатель во время перерыва с подсказками, которые приведут его к ответу. Третий тип гипотез был назван гипотезами ухода внимания. Они опираются на детальный анализ процесса решения инсайтных задач (Segal, 2004). Далее мы рассмотрим подробнее существующие объяснения феномена инкубации и их экспериментальные свидетельства, структурируя их в соответствии с описанной выше классификацией.

\section{Гипотезы автономных прочессов}

Одно из наиболее простых объяснений инкубации - әипотеза рассеяния усталости или гипотеза истощения ресурса. Перерыв в решении задачи, согласно этой гипотезе, позволяет человеку отдохнуть после первых попыток решения (Seifert et al., 1995). Данная гипотеза не нашла подтверждений в эмпирических исследованиях, более того, некоторые факты указывают на то, что отдых не может быть единственным механизмом, обеспечивающим эффект инкубации. Во-первых, инкубация помогает даже в тех случаях, когда испытуемые не отдыхают, а решают сложные задачи (Segal, 2004). Во-вторых, существуют исследования, в которых группы испытуемых отличались по выраженности эффекта инкубации, несмотря на то, что длительность и содержание перерыва были у всех одинаковы (Dodds et al., 2002).

Гипотеза сознательной работы возникла благодаря наблюдениям Р. Вейсберга, который заметил, что люди могут быстро забывать о сознательно совершенных мыслях и действиях. Следовательно, можно предположить, что при решении творческой задачи человек находит ответ в те моменты, когда сознательно возвращается к задаче во время перерыва, но не замечает этого и полагает, что действует неосознанно (Weisberg, 2006, p. 443-445). Данная гипотеза была проверена в экспериментах К. Гилхули и его коллег. Авторы предположили, что сознательная работа над основной задачей во время инкубации будет приводить к уменьшению эффективности решения инкубационной задачи в экспериментальной группе по сравнению с контрольной группой, которая решала только инкубационную задачу. В их экспериментах 
наблюдался эффект инкубации, при этом не было обнаружено уменьшения эффективности решения инкубационных задач в экспериментальной группе по сравнению с контрольной (Gilhooly et al., 2012, 2014). В исследовании Б. Бейрд испытуемые давали самоотчет о частоте возникновения сознательных мыслей, связанных с целевой задачей, появляющихся во время периода инкубации. Результаты показали, что число сознательных мыслей не было связано с успешностью решения основной задачи после перерыва (Baird et al., 2012). Таким образом, гипотеза сознательной работы не нашла подтверждений в экспериментальных исследованиях.

Одним из наиболее значимых и перспективных объяснений эффекта инкубации является гипотеза селективного забывания или гипотеза забывания фиксащий (Smith, 2011). Теоретические идеи, которые составляют ее смысловую основу, можно встретить в работах гештальтпсихологов (Köhler, 1947; Duncker, 1945). Они полагали, что решатель может быть фиксирован на неверных ответах вследствие своего прошлого опыта. Фиксированность выражается в том, что человек предпочитает решать задачу неуместным способом, являющимся препятствием для возникновения инсайта (Smith, 1995). В работе Р. Вудвортса и Г. Шлосберга были высказаны идеи о том, что инкубация может способствовать решению задачи благодаря механизму забывания фиксаций: «Когда мыслящий делает неправильный старт, то он не чувствует, как падает в яму, из которой не способен выбраться в данный момент... Инкубационный период дает время для того, чтобы ошибочная установка исчезла, и позволяет мыслящему бросить новый взгляд на проблему» (Woodworth, Schlosberg, 1954, p. 841).

Эти взгляды на механизмы инкубации нашли немало доказательств в экспериментах. Рассмотрим одну из наиболее известных работ, проведенную в рамках гипотезы селективного забывания, авторами которой являются С. Смит и С. Бланкеншип. Они провели эксперимент, в котором в качестве стимульного материала использовались ребусы. Перед началом решения испытуемых фиксировали на стимулах, отвлекающих от искомого ответа. Результаты эксперимента показали увеличение успешности решения ребусов после инкубации в экспериментальной группе по сравнению с контрольной, которое сопровождалось забыванием ложных подсказок (Smith, Blankenship, 1989).

В другом исследовании тех же авторов (Smith, Blankenship, 1991) в качестве стимульного материала использовались задания теста отдаленных ассоциаций (Mednick, 1962). Результаты эксперимента показали, что эффект инкубации наблюдался только в том случае, когда испытуемые были фиксированы на отвлекающих подсказках (Smith, 2011). Существуют и другие исследования, в которых эффект инкубации удавалось получить только при наличии фиксированности (Vul, Pashler, 2007; Kohn, Smith, 2009; Penaloza, Calvillo, 2012).

С одной стороны, в исследованиях было обнаружено немало фактов, подкрепляющих гипотезу селективного забывания. Тем не менее эта гипотеза не может объяснить те случаи, когда эффект инкубации наблюдался при отсутствии предварительной фиксации на неверных решениях. Такие случаи 
лучше объясняются гипотезой бессознательной работы, идеи которой можно найти еще в ранней описательной модели инкубации А. Пуанкаре, предположившего работу бессознательного процесса во время отвлечения внимания от задачи (Пуанкаре, 1981). Сторонники этой теории полагают, что во время инкубации происходят неосознанные процессы, которые приводят человека к правильному ответу. В чем же именно заключается неосознанная работа, способствующая нахождению решения? На этот вопрос исследователи пока не нашли определенного ответа. Некоторые авторы предполагали, что во время периода инкубации происходит процесс распространения активации в семантической сети, благодаря которому может произойти активация верного решения (Bowers et al., 1990; Yaniv, Meyer, 1987). Но в исследованиях не было получено результатов, свидетельствующих о правильности их предположений (Sio, Rudowicz, 2007).

Тем не менее во многих работах последних десятилетий было показано, что отвлечение внимания от решения задачи может облегчать поиск ответа (Dijksterhuis, Meurs, 2006; Nordgren et al., 2011; Gilhooly et al., 2012). В одном из этих экспериментов задача испытуемых состояла в придумывании оригинальных названий для различных блюд. В инструкции было дано несколько примеров названий, которые оканчивались на букву «i». Первая группа участников приступала к задаче сразу же после прочтения инструкции, вторая после трех минут сознательного обдумывания проблемы, а третья группа делала инкубационный перерыв, во время которого решала другое задание. Было обнаружено увеличение числа сгенерированных ответов во второй группе по сравнению с двумя другими группами, а также увеличение оригинальности сгенерированных ответов в третьей группе. Оригинальность вычислялась по количеству ответов, которые не заканчивались на букву «і». При объяснении этих результатов авторы опираются на следующую модель. Они полагают, что мышление можно условно разделить на два процесса сознательный и бессознательный. Сознательный процесс предполагает фокусировку внимания на целевой задаче и использование логических преобразований, тогда как бессознательный процесс необходим для творчества. Он предполагает расфокусировку внимания, способствующую поиску и интегрированию разнородной информации, бо́льшая часть которой недоступна для сознательного процесса (Dijksterhuis, Meurs, 2006).

Гипотеза бессознательной работы получила немало подтверждений и в других экспериментах (Gilhooly, 2016; Helie et al., 2008), а в метааналитической работе M. Стрик с коллегами было показано, что эффект бессознательной работы существует (Strick et al., 2011). Тем не менее до сих пор не прояснено, какие именно механизмы лежат в его основе.

\section{Гипотезы внешних ключей}

Успех в решении задачи зачастую зависит от того, заметит ли человек в явлениях окружающей среды то, что наведет его на правильную мысль. Один из наиболее ярких примеров - внезапное открытие Архимедом способа 
вычисления плотности вещества, которое произошло в тот момент, когда он погрузился в ванную и заметил повышение уровня воды (Валуева, Ушаков, 2015).

Некоторые исследователи инкубации предположили, что перерыв в решении помогает благодаря тому, что человек, отвлекаясь от задачи, находит подсказки в окружающей среде (Yaniv, Meyer, 1987; Seifert et al., 1995). Одна из наиболее известных гипотез этого типа принадлежит К. Сейферт. Согласно ее теории спонтанной ассимилящии (opportunistic assimilation theory), в тот момент, когда решение задачи заходит в тупик, формируются «маркеры неудачи». Они представляют собой репрезентации различных характеристик проблемы в долговременной памяти. Инсайт происходит в том случае, если произошла встреча с внешними стимулами, которые ассимилируются когнитивной системой при их соответствии «маркерам неудачи» (Seifert et al., 1995). Эти представления проверялись некоторыми авторами (Dominowski, Jenrick, 1972; Olton, Johnson, 1976; Mednick et al., 1964; Dorfman, 1990). В экспериментах М. Медник и Дж. Дорфман в качестве стимульного материала использовался тест отдаленных ассоциаций и во время периода инкубации испытуемым давались подсказки к заданиям. Результаты показали, что получение подсказок способствует нахождению верного ответа, но эффекта инкубации не наблюдалось. В эксперименте Р. Доддс был получен эффект инкубации, но он наблюдался только в том случае, когда испытуемым давалось задание использовать подсказки (Dodds et al., 2002).

Описанные выше результаты не согласуются с гипотезами внешних ключей, которые предполагают, что эффект инкубации связан с получением подсказок. Если бы они были верны, то наблюдалось бы значимое улучшение успешности решения задач после перерыва. Метаанализ У. Сио и Т. Ормерода также показывает, что получение подсказок не является обязательным условием успешной инкубации (Sio, Ormerod, 2009).

\section{Гипотезы ухода внимания}

Гипотезы ухода внимания базируются на представлениях, которые высказывались гештальтпсихологами (Köhler, 1969; Wertheimer, 1959), а также сторонниками теории переработки информации (Newell, Simon, 1972; Ohlsson, 1992). Для нахождения ответа на задачу необходимо изначально сделать верное организующее предположение, которое свяжет элементы задачи таким образом, что они образуют целостную структуру. Но, приступая к решению задачи, человек может сделать неверное организующее предположение, из-за чего решение зайдет в тупик (Wertheimer, 1959). Сторонники гипотез ухода внимания рассматривают инкубационный перерыв как способ преодоления тупика. Он способствует переключению внимания из ложного организующего предположения, благодаря чему фиксация на нем устраняется, появляется возможность сформировать новое верное предположение (Ohlsson, 1992).

Можно заметить некоторое сходство этих идей с описанной ранее гипотезой забывания фиксаций, которая также предполагает устранение фиксаций, 
мешающих нахождению верного ответа (Smith, 1995). Тем не менее сторонники гипотез ухода внимания считают, что во время инкубации происходит мгновенное переструктурирование репрезентации задачи, а не постепенное забывание фиксаций (Segal, 2004). Согласно этой точке зрения, которая была названа К. Гилхули «свежий взгляд», для устранения ложных установок достаточно просто убрать внимание с задачи, что даст возможность взглянуть на проблему по-новому (Gilhooly, 2016).

Для экспериментальной проверки этих предположений Е. Сигал использовал различные по длительности и содержанию инкубационные задачи. В том случае, если рассматриваемые предположения верны, то сложность инкубационной задачи должна оказать влияние на величину эффекта инкубации, поскольку переключение на сложную задачу с большей вероятностью уберет внимание с ложного предположения, чем переключение на легкую. При этом длительность перерыва не должна влиять на выраженность эффекта инкубации, поскольку переключение внимания должно происходить одномоментно. Данные, полученные в эксперименте, соответствовали предсказаниям (Segal, 2004).

Исследование когнитивных механизмов инкубации с позиции гипотезы ухода внимания является перспективным, но, несмотря на наличие экспериментальных фактов, подтверждающих эту гипотезу, ее доказательная база еще слишком мала для построения каких-либо детальных моделей.

\section{Результаты обзорных и метааналитических работ}

Помимо отдельных экспериментальных работ, существует также несколько обзорных (Dodds et al., 2003; Gilhooly, 2016) и метааналитических работ (Sio, Ormerod, 2009; Strick et al., 2011), которые структурируют и обобщают имеющиеся в психологии данные. В этих работах было доказано существование эффекта инкубации, а также был произведен детальный анализ факторов, влияющих на его выраженность, в частности, влияние типа основной задачи.

В исследовании У. Сио и Т. Ормерода отдельно вычислялась величина эффекта инкубации при решении заданий на дивергентное мышление, инсайтных, лингвистических, зрительно-пространственных задач. Длительность подготовительного этапа оказалась значимой для многих типов задач, а инкубационного этапа - только в случае заданий на дивергентное мышление, что свидетельствует о значимости процесса распространения активации по семантической сети и доказывает правомерность теории бессознательной работы (Sio, Ormerod, 2009). Использование легкой задачи в качестве инкубационной оказывало положительное влияние на эффект (Strick et al., 2011), чаще всего это наблюдалось при решении лингвистических задач, таких, например, как тест отдаленных ассоциаций (Sio, Ormerod, 2009). Авторы приводят объяснение этого факта в рамках гипотезы забывания фиксаций и предполагают, что задача с низкой когнитивной нагрузкой, требующая расфокусировки внимания, способствует устранению влияния фиксаций. 


\section{Современные нейрокогнитивные исследования}

В последние десятилетия актуальным направлением становится изучение нейрокогнитивных основ мышления, в частности творческого. Внедрение таких психофизиологических методов исследования, как функциональная магниторезонансная (фМРТ) и позитронно-эмиссионная (ПЭТ) томография, способствовало в начале XXI в. открытию дефолтной системы мозга (англ. default mode network), которая участвует в мыслительных процессах в те периоды, когда человек находится в покое и не занят переработкой информации из внешней среды. Эта система включает медиальную префронтальную кору, заднюю поясную извилину, прекунеус, нижнюю часть теменной коры и гиппокампальную формацию (Ushakov et al., 2016).

Многие авторы указывают на значимую роль этой системы при решении творческих задач (Beaty et al., 2017; Goldberg, 2018), а в ряде работ было продемонстрировано, что увеличение креативности ответов сопровождается увеличением активации областей, являющихся частью дефолтной системы мозга (Saggar et al., 2017; Marron et al., 2018). В новых исследованиях ставится задача выявить активность сетей покоя во время периода инкубации с использованием усовершенствованного метода электроэнцефалографии (ЭЭГ). Особую роль на стадии инкубации, по-видимому, играют низкочастотные колебания электрофизиологических процессов, связанные с правым полушарием (Князев и др., 2020б).

Однако существуют работы, в которых показано, что решение задач на креативность нельзя объяснить только работой дефолтной системы мозга (Величковский и др., 2019, 2020). В частности, в момент инсайта была обнаружена активность в других областях мозга, например, в моторных зонах (Ogawa et al., 2018) и в правой верхней височной извилине (Kounios, Beeman, 2014). Особое значение может иметь взаимодействие дефолтной системы с двумя другими «нейросетями покоя», а именно с расположенной в вентральных областях коры системой значимости (salience) и с локализованной более дорсально системой исполнительного внимания. Например, при успешной инкубации наблюдается усиление активности сети значимости одновременно с ослаблением активности сети внимания, свидетельствующее о том, что внимание приобретает рассеянный в пространстве (или амбиентный) характер (Князев и др., 2020а). Таким образом, в этой области накопилось много не всегда однозначных данных, что ставит задачу детального изучения нейрокогнитивных механизмов инкубации и инсайта.

\section{Заключение}

Обзор исследований, посвященных проблеме инкубации при решении творческих задач, показывает, что наибольшее число экспериментальных подтверждений получили гипотеза бессознательной работы и гипотеза селективного забывания. С одной стороны, было выявлено, что эффект инкубации чаще всего наблюдается в тех случаях, когда у испытуемого имелись фикса- 
ции на ложных подсказках (Smith, Blankenship, 1989, 1991). С другой стороны, некоторые работы демонстрируют наличие эффекта даже в тех случаях, когда фиксации отсутствовали (Dijksterhuis, Meurs, 2006; Nordgren et al., 2011). Вероятно, что затруднение в нахождении ответа на задачу может быть связано как с имеющимися фиксациями на неверных решениях, так и с невозможностью найти новые идеи, а инкубационный перерыв помогает в случае обеих проблем.

Несмотря на многочисленные открытия, остается еще немало вопросов, на которые пока нет точного ответа. Например, до сих пор не прояснены механизмы бессознательной работы во время периода инкубации (Nordgren et al., 2011). А рассмотрение гипотез ухода внимания заставляет усомниться в том, что влияние фиксации устраняется именно за счет забывания (Segal, 2004). Также остается открытым вопрос о сходстве и различии механизмов сна и инкубации. Некоторые ученые утверждают, что совершили свои открытия благодаря сну. Например, О. Леви, известный физиолог и фармаколог, получивший Нобелевскую премию за открытия, связанные с химической передачей нервных импульсов (Dement, 1974, p. 98), а также немецкий химик Ф.А. Кекуле, предложивший шестиугольную структуру молекулы бензола, которая приснилась ему в виде яркого образа (Ramsay, Rocke, 1984). Данные современных исследований спорны. Были обнаружены доказательства положительного влияния фазы быстрого сна на решение творческих задач (Cai et al., 2009), однако в некоторых работах показано, что это происходит за счет механизмов, отличных от инкубационных (Landmann et al., 2016), и не во всех работах был выявлен подобный эффект (Brodt et al., 2018).

Возможно, использование новейших методов изучения работы мозга в процессе решения творческих задач поможет пролить свет на эту важнейшую область психологии мышления (Величковский и др., 2019). Мы надеемся, что настоящий обзор позволяет наметить ориентиры для проведения дальнейших продуктивных исследований.

\section{Литература}

Бюлер, В. (1989). Гаусс: Биографическое исследование. М.: Наука.

Валуева, Е. А. (2016). Роль инкубационного периода в решении задач. Психология. Журнал Высшей школь экономики, 13(4), 789-800.

Валуева Е. А., Ушаков Д. В. (2015). Сигнальная модель инсайта: от исторических предпосылок к эмпирическим предсказаниям. В кн. А. Л. Журавлев, Д. В. Ушаков, М. А. Холодная (ред.), Современные исследования интеллекта и творчества (с. 15-47). М.: Издательство «Институт психологии РАН».

Валуева, Е. А., Ушаков, Д. В. (2017). Инсайт и инкубация в мышлении: роль процессов осознавания. Сибирский психологический журнал, 63, 19-35.

Величковский, Б. М., Князев, Г. Г. Валуева, Е. А., Ушаков, Д. В. (2019). Новые подходы в исследованиях творческого мышления: от феноменологии инсайта к объективным методам и нейросетевым моделям. Вопросы психологии, 3, 3-16. 
Величковский, Б. М., Осипов, Г. С., Носовец, З. А., Величковский, Б. Б. (2020). Личностный смысл и решение творческих задач: современные нейрокогнитивные исследования. Искусственный интеллект и принятие решений, 3, 3-14.

Князев, Г. Г., Бочаров, А. В., Савостьянов, А. Н., Величковский, Б. М. (2020, а). Эффект инкубации и активность сетей покоя. Журнал высшей нервной деятельности им. И.П. Павлова, 70(5), 601-608.

Князев, Г. Г., Бочаров, А. В., Савостьянов, А. Н., Ушаков, Д. В., Величковский, Б. М. (2020, б). Электроэнцефалографические корреляты инсайта. Вопросы психологии, 1, 119-132.

Коровкин, С. Ю., Савинова, А. Д., Владимиров, И. Ю. (2016). Мониторинг динамики загрузки рабочей памяти на этапе инкубации инсайтного решения. Вопросы психологии, 2, 148-161.

Лапшин, И. И. (1999). Философия изобретения и изобретение в философии. М.: Республика.

Пономарев Я. А. (1967). Психика и интуиция. М.: Политиздат.

Пуанкаре, А. (1981). Математическое открытие. В кн. Хрестоматия по общей психологии. Психология мышиения (с. 356-365). М.: Изд-во Московского университета, 1981.

Ушаков, Д. В. (2000). Творчество и «дарвиновский» способ его описания. Психологический журнал, 20(3), 103-110.

Ушаков, Д. В. (2006). Языки психологии творчества: Яков Александрович Пономарев и его научная школа. В кн. Д. В. Ушаков (ред.), Психология творчества: икола Я. А. Пономарева (с. 19-142). М.: Издательство «Институт психологии РАН».

Ссылки на зарубежные источники см. в разделе References после англоязычного блока.

Лаптева Надежда Михайловна - младший научный сотрудник, ФГБУН «Институт психологии Российской академии наук».

Сфера научных интересов: креативность, когнитивная психология, психофизиология, воплощенное познание.

Контакты: n.m.lapteva@mail.ru

\title{
Incubation Period in Creative Problem Solving: Hypotheses and Research Prospects
}

\author{
N.M. Lapteva \\ ${ }^{a}$ Institute of Psychology, Russian Academy of Sciences, 13 build. 1, Yaroslavskaya Str., Moscow, 129366, \\ Russian Federation
}

\begin{abstract}
The present article is devoted to the famous phenomenon in the psychology of creativity, incubation during creative problem solving. Incubation is a break in problem solving, which facilitates efficiency despite the absence of a conscious search. This article introduces a review of the theoretical frameworks and experimental studies of incubation and its cognitive mechanisms. The author describes the main hypotheses about the cognitive mechanisms of the incubation period (such as the forgetting fixation hypothesis, the unconscious work hypothesis, the external
\end{abstract}


cues hypothesis, the attention withdrawal hypothesis), and their empirical evidence. Our theoretical review also contains the main conclusions from meta-analyses, which demonstrate evidence for the incubation effect, and the analysis of the factors affecting the incubation effect size, specifically the type of the main task and the type of the incubation task, the length of the preparatory stage and the length of the incubation phase. Special attention is given to the description of modern neurocognitive studies of creative thinking. These studies aim to investigate the brain systems activated during the incubation period and make it possible to analyze this stage of a creative process in a more detailed way. Incubation is found to be associated with the increased default mode network activity, salience network activity, and activity in motor areas and with the decreased executive attention system activity. In conclusion, the author outlines the conflicting and understudied areas in the theoretical representations of the incubation process that provide prospective directions for future research.

Keywords: creativity, incubation, forgetting fixation hypothesis, unconscious work hypothesis, default mode network, neurophysiological mechanisms.

\section{References}

Baird, B., Smallwood, J., Mrazek, M. D., Kam, J. W. Y., Franklin, M. S., \& Schooler, J. W. (2012). Inspired by distraction: Mind wandering facilitates creative incubation. Psychological Science, 23(10), 1117-1122. doi:10.1177/0956797612446024

Beaty, R. E., Christensen, A. P., Benedek, M., Silvia, P. J., \& Schacter, D. L. (2017). Creative constraints: Brain activity and network dynamics underlying semantic interference during idea production. NeuroImage, 148, 189-196. doi:10.1016/j.neuroimage.2017.01.012

Bowers, K. S., Regher, G., Balthazard, C., \& Parker, K. (1990). Intuition in the context of discovery. Cognitive Psychology, 22, 72-110.

Brodt, S., Pöhlchen, D., Täumer, E., Gais, S., \& Schönauer, M. (2018). Incubation, not sleep, aids problem-solving. Sleep, 41(10), 1-11. doi:10.1093/sleep/zsy155

Bühler, W. K. (1989). Gauss: Biograficheskoe issledovanie [Gauss: a biographical study]. Moscow: Nauka. (in Russian; transl. of: Bühler, W. K. (1981). Gauss: a biographical study. Berlin/New York: Springer-Verlag.)

Cai, D. J., Mednick, S. A., Harrison, E. M., Kanady, J. C., \& Mednick, S. C. (2009). REM, not incubation, improves creativity by priming associative networks. Proceedings of the National Academy of Sciences of the USA, 106(25), 10130-10134. doi:10.1073/pnas.0900271106

Dement, W. C. (1974). Problem solving. In W. C. Dement, Some must watch while some must sleep (pp. 98-102). San Francisco: W. H. Freeman.

Dijksterhuis, A., \& Meurs, T. (2006). Where creativity resides: the generative power of unconscious thought. Consciousness and Cognition, 15(1), 135-146. doi:10.1016/j.concog.2005.04.007

Dodds, R. A., Smith, S. M., \& Ward, T. B. (2002). The use of environmental clues during incubation. Creativity Research Journal, 14(3-4), 287-304. doi:10.1207/s15326934crj1434_1

Dodds, R. A., Ward, T. B., \& Smith, S. M. (2003). A review of the experimental literature on incubation in problem solving and creativity. In M. A. Runco (Ed.), Creativity research handbook (Vol. 3, pp. 285-302). Cresskill, NJ: HamptonPress. doi:10.1002/j.2162-6057.2009.tb01309.x

Dominowski, R., \& Jenrick, R. (1972). Effects of hints and interpolated activity on solution of an insight problem. Bulletin of the Psychonomic Society, 26, 335-338. 
Dorfman, J. (1990). Metacognition and incubation effects in insight problem solving (Unpublished doctoral dissertation). University of California, San Diego, CA.

Duncker, K. (1945). On problem-solving. Psychological Monographs, 58(5), i-113. doi:10.1037/h0093599

Gilhooly, K. J. (2016). Incubation and intuition in creative problem solving. Frontiers in Psychology, 7 , 1076. doi:10.3389/fpsyg.2016.01076

Gilhooly, K. J., Georgiou, G. J., Garrison, J., Reston, J. D., \& Sirota, M. (2012). Don't wait to incubate: Immediate versus delayed incubation in divergent thinking. Memory and Cognition, 40, 966-975. doi:10.3758/s13421-012-0199-z

Gilhooly, K. J., Georgiou, G. J., Sirota, M., \& Paphiti-Galeano, A. (2014). Incubation and suppression processes in creative problem solving. Thinking and Reasoning, 21(1), 130-146. doi:10.1080/13546783.2014.953581

Goldberg, E. (2018). Creativity: The human brain in the age of innovation. New York: Oxford Univercity Press.

Helie, S., Sun, R., \& Xiong, L. (2008). Mixed effects of distractor tasks on incubation. In B. C. Love, K. McRae, \& V. M. Sloutsky (Eds.), Proceedings of the 30th Annual Meeting of the Cognitive Science Society (pp. 1251-1256). Austin, TX: Cognitive Science Society.

Knyazev, G. G., Bocharov, A. V., Savost'yanov, A. N., Ushakov, D. V., \& Velichkovsky, B. M. (2020, b). Elektroentsefalograficheskie korrelyaty insaita [Electroencephalographic correlates of insight]. Voprosy Psikhologii, 1, 119-132. (in Russian)

Knyazev, G. G., Bocharov, A. V., Savost'yanov, A. N., \& Velichkovsky, B. M. (2020, a). Effekt inkubatsii i aktivnost' setei pokoya [The effect of incubation and activity of default mode networks]. Zhurnal Vysshei Neronoi Deyatelnosti Imeni I.P. Pavlova, 70(5), 601-608. (in Russian)

Köhler, W. (1947). Gestalt psychology: An introduction to new concepts in modern psychology. New York: Liveright Pub. Corp.

Köhler, W. (1969). The task of Gestalt psychology. Princeton, NJ: Princeton University Press.

Kohn, N., \& Smith, S. M. (2009). Partly versus completely out of your mind: Effects of incubation and distraction on resolving fixation. The Journal of Creative Behavior, 43(2), 102-118.

Korovkin, S. Yu., Savinova, A. D., \& Vladimirov, I. Yu. (2016). Monitoring dynamics of loading of the working memory in the incubation stage of an insight. Voprosy Psikhologii, 2, 148-161. (in Russian)

Kounios, J., \& Beeman, M. (2014). The cognitive neuroscience of insight. Annual Review of Psychology, 65, 71-93. doi:10.1146/annurev-psych-010213-115154

Landmann, N., Kuhn, M., Maier, J. G., Feige, B., Spiegelhalder, K., Riemann, D., \& Nissen, C. (2016). Sleep strengthens but does not reorganize memory traces in a verbal creativity task. Sleep, 39(3), 705-713. doi:10.5665/sleep.5556

Lapshin, I. I. (1999). Filosofiya izobreteniya i izobretenie v filosofii [Philosophy of invention and invention in philosophy]. Moscow: Respublika. (in Russian)

Marron, T. R., Lerner, Y., Berant, E., Kinreich, S., Shapira-Lichter, I., Hendler, T., \& Faust, M. (2018). Chain free association, creativity, and the default mode network. Neuropsychologia, 118, 40-58. doi:10.1016/j.neuropsychologia.2018.03.018

Mednick, M., Mednick, S., \& Mednick, E. (1964). Incubation of creative performance and specific associative priming. Journal of Abnormal and Social Psychology, 69, 84-88. doi:10.1037/h0045994

Mednick, S. A. (1962). The associative basis of the creative process. Psychological Review, 69, 220-232. doi:10.1037/h0048850 
Newell, A., \& Simon, H. A. (1972). Human problem solving. Englewood Cliffs, NJ: Prentice-Hall.

Nordgren, L. F., Maarten, W. B., \& Dijksterhuis, A. (2011). The best of both worlds: Integrating conscious and unconscious thought best solves complex decisions. Journal of Experimental Social Psychology, 47(2), 509-511. doi:10.1016/j.jesp.2010.12.007

Ogawa, T., Aihara, T., Shimokawa, T., \& Yamashita, O. (2018). Large-scale brain network associated with creative insight: Combined voxel-based morphometry and resting-state functional connectivity analyses. Scientific Reports, 8, 6477. doi:10.1038/s41598-018-24981-0

Ohlsson, S. (1992). Information processing explanations of insight and related phenomena. In M. T. Keane \& K. J. Gilhooley (Eds.), Advances in the psychology of thinking (Vol. 1, pp. 1-44). London: Harvester-Wheatsheaf.

Olton, R. M., \& Johnson, D. M. (1976). Mechanisms of incubation in creative problem solving. American Journal of Psychology, 89, 617-630.

Penaloza, A. A., \& Calvillo, D. P. (2012). Incubation provides relief from artificial fixation in problem solving. Creativity Research Journal, 24(4), 338-344. doi:10.1080/10400419.2012.730329

Poincaré, H. (1981). Matematicheskoe otkrytie [Mathematical discovery]. In Khrestomatiya po obshchei psikhologii. Psikhologiya myshleniya [A reader in general psychology. The psychology of thinking] (pp. 356-365). Moscow: Moscow University Press, 1981. (in Russian)

Ponomarev, Y. A. (1967). Psikhika i intuitsiya [Psyche and intuition]. Moscow: Politizdat. (in Russian)

Ramsay, O. B., \& Rocke, A. J. (1984). Kekule's dreams: Separating the fiction from the fact. Chemistry in Britain, 20, 1093-1094.

Saggar, M., Quintin, E. M., Bott, N. T., Kienitz, E., Chien, Y. H., Hong, D. W., ... Reiss, A. L. (2017). Changes in brain activation associated with spontaneous improvization and figural creativity after design-thinking-based training: A longitudinal fMRI Study. Cerebral Cortex, 27(7), 3542-3552. doi:10.1093/cercor/bhw171

Segal, E. (2004). Incubation in insight problem solving. Creativity Research Journal, 16(1), 141-148.

Seifert, C. M., Meyer, D. E., Davidson, N., Patalano, A. L., \& Yaniv, I. (1995). Demystification of cognitive insight: Opportunistic assimilation and the prepared-mind hypothesis. In R. J. Sternberg \& J. E. Davidson (Eds.), The nature of insight (pp. 65-124). Cambridge, MA: The MIT Press.

Sio, U. N., \& Ormerod, T. C. (2009). Does incubation enhance problem solving? A meta-analytic review. Psychological Bulletin, 135(1), 94-120. doi:10.1037/a0014212

Sio, U. N., \& Rudowicz, E. (2007). The role of an incubation period in creative problem solving. Creativity Research Journal, 19(2-3), 307-318. doi:10.1080/10400410701397453

Smith, S. M. (1995). Getting into and out of mental ruts: a theory of fixation, incubation, and insight. In R. J. Sternberg \& J. E. Davidson (Eds.), The nature of insight (pp. 229-251). Cambridge, MA: The MIT Press.

Smith, S. M. (2011). Incubation. In M. A. Runco \& S. R. Pritzker (Eds.), Encyclopedia of creativity ( $2^{\text {nd }}$ ed., Vol. 1, pp. 653-657). Academic Press.

Smith, S. M., \& Blankenship, S. E. (1989). Incubation effects. Bulletin of the Psychonomic Society, 27, 311-314. doi:10.3758/BF03334612

Smith, S. M., \& Blankenship, S. E. (1991). Incubation and the persistence of fixation in problem solving. American Journal of Psychology, 104(1), 61-87. doi:10.2307/1422851

Strick, M., Dijksterhuis, A., Bos, M. W., Sjoerdsma, A., VanBaaren, R. B., \& Nordgren, L. F. (2011). A meta-analysis on unconscious thought effects. Social Cognition, 29(6), 738-762. doi:10.1521/soco.2011.29.6.738 
Ushakov, D. V. (2000). Creativity and "Darwinian" way of its description. Psikhologicheskii Zhurnal, 21(3), 110-111. (in Russian)

Ushakov, D. V. (2006). Yazyki psikhologii tvorchestva: Yakov Aleksandrovich Ponomarev i ego nauchnaya shkola [Languages of creative psychology: Yakov Aleksandrovich Ponomarev and his scientific school]. In D. V. Ushakov (Eds.), Psikhologiya tvorchestva: shkola Y. A. Ponomareva [Psychology of creativity: the school of Y. A. Ponomarev] (pp. 19-142). Moscow: Institute of Psychology of the RAS. (in Russian)

Ushakov, V. L., Sharaev, M. G., Kartashov, S. I., Zavyalova, V. V., Verkhlyutov, V. M., \& Velichkovsky, B. M. (2016). Dynamic causal modeling of hippocampal links within the human default mode network: Lateralization and computational stability of effective connections. Frontiers in Human Neuroscience, 10, Art. 528. doi:10.3389/fnhum.2016.00528

Valueva, E. A. (2016). The role of incubation period in problem solving. Psychology. Journal of Higher School of Economics, 13(4), 789-800. (in Russian)

Valueva E. A., \& Ushakov D. V. (2015). Signal'naya model' insaita: ot istoricheskikh predposylok k empiricheskim predskazaniyam [Signal model of insight: from historical backgrounds to empirical predictions]. In A. L. Zhuravlev, D. V. Ushakov, \& M. A. Kholodnaya (Eds.), Sovremennye issledovaniya intellekta i tvorchestva [Modern research on intelligence and creativity] (pp. 15-47). Moscow: Institute of Psychology of the RAS. (in Russian)

Valueva, E. A., \& Ushakov, D. V. (2017). Insight and incubation in thinking: the role of awareness processes. Sibirskii Psikhologicheskii Zhurnal [Siberian Journal of Psychology], 63, 19-35. (in Russian)

Velichkovsky, B. M., Knyzev, G. G., Valueva, E. A., \& Ushakov, D. V. (2019). New approaches in studies of creative thinking: Prom phenomenology of insight to objective methods and neuronetwork models. Voprosy Psikhologii, 3, 3-16. (in Russian)

Velichkovsky, B. M., Osipov, G. S., Nosovetz, Z. A., \& Velichkovsky, B. B. (2020). Personal sense and solution of creative tasks: contemporary neurocognitive studies. Iskusstvennyi Intellekt $i$ Prinyatie Reshenii [Artificial Intelligence and Decision Making], 3, 3-14. (in Russian)

Vul, E., \& Pashler, H. (2007). Incubation benefits only after people have been misdirected. Memory and Cognition, 35(4), 701-710. doi:10.3758/BF03193308

Wallas, G. (1926). The art of thought. New York: Harcourt Brace Jovanovich.

Weisberg, R. W. (2006). Creativity: Understanding innovation in problem solving, science, invention, and the arts. New York: J. Wiley \& Sons.

Wertheimer, M. (1959). Productive thinking. New York: Harper \& Row.

Woodworth, R., \& Schlosberg, H. (1954). Experimental psychology (2nd ed.). New York: Holt, Rinehart \& Winston.

Yaniv, I., \& Meyer, D. E. (1987). Activation and metacognition of inaccessible stored information: Potential bases of incubation effects in problem solving. Journal of Experimental Psychology: Learning, Memory, and Cognition, 13, 187-205. doi:10.1037/0278-7393.13.2.187

Nadezhda M. Lapteva - Junior Research Fellow, Institute of Psychology, Russian Academy of Sciences.

Research area: creativity, cognitive psychology, psychophysiology, embodied cognition.

E-mail: n.m.lapteva@mail.ru 